Published in final edited form as:

J Behav Med. 2014 October ; 37(5): 819-827. doi:10.1007/s10865-013-9542-5.

\title{
Financial motivation undermines potential enjoyment in an intensive diet and activity intervention
}

\author{
Arlen C. Moller, \\ Department of Psychology, Illinois Institute of Technology, Chicago, IL, USA \\ Department of Preventive Medicine, Northwestern University, Chicago, IL, USA \\ Joanna Buscemi, \\ Department of Preventive Medicine, Northwestern University, Chicago, IL, USA \\ Institute for Health Research and Policy, University of Illinois at Chicago, Chicago, IL, USA \\ H. Gene McFadden, \\ Department of Preventive Medicine, Northwestern University, Chicago, IL, USA \\ Donald Hedeker, and \\ Division of Epidemiology and Biostatistics, University of Illinois at Chicago, Chicago, IL, USA \\ Bonnie Spring \\ Department of Preventive Medicine, Northwestern University, Chicago, IL, USA
}

\begin{abstract}
The use of material incentives in healthy lifestyle interventions is becoming widespread. However, self-determination theory (SDT) posits that when material incentives are perceived as controlling, they undermine intrinsic motivation. We analyzed data from the Make Better Choices trial一a trial testing strategies for improving four risk behaviors: low fruit-vegetable intake, high saturated fat intake, low physical activity, and high sedentary activity. At baseline, participants reported the degree to which financial incentives were an important motivator (financial motivation); selfreported enjoyment of each behavior was assessed before and after the 3-week incentivization phase. Consistent with SDT, after controlling for general motivation and group assignment, lower financial motivation predicted more adaptive changes in enjoyment. Whereas participants low in financial motivation experienced adaptive changes, adaptive changes were suppressed among those high in financial motivation.
\end{abstract}

\section{Keywords}

Financial incentives; Intrinsic motivation; Affect; Undermining; Diet; Physical activity

\footnotetext{
(C) Springer Science+Business Media New York 2013
} amoller@iit.edu. 


\section{Introduction}

\section{Financial incentives in healthy lifestyle interventions}

The use of tangible extrinsic rewards - such as financial or monetary incentives - to help motivate adherence and performance in healthy lifestyle interventions is a practice that is widespread, and by many indications, growing in prevalence. In research contexts, most healthy lifestyle interventions targeting diet and/or activity and lasting more than a few days include some form of extrinsic compensation for participating (e.g., course credit, money, or gifts), either for attendance, or in other cases for achieving the targeted health behavior change itself. Historically, in clinical practice, patients have been expected to pay for healthy lifestyle treatments. However, more recently, this dynamic has changed, particularly in the context of employer sponsored health and wellness programs. The rising cost of health care has placed an increased burden on employers who provide health insurance benefits to their employees, and many employers have embraced financial incentives as a tool to help motivate healthy lifestyle changes among their employees (National Business Group on Health and Fidelity Investments Benefits Consulting, 2013).

\section{Financial incentives and maintenance of healthy behavior change}

Extrinsic material incentives are a powerful tool for motivating the initiation of changes in human behavior, especially for behaviors for which there is little motivation at baseline (Skinner, 1974). Contingency management therapy, based on the behavioral principle of reinforcement, has been shown especially effective at improving outcomes in substance abuse treatment (see Lussier et al., 2006). However, contingency management strategies have so far proven relatively less effective at achieving sustainable changes in other health behaviors, such as improving diet, increasing physical activity, and weight management (Burns et al., 2012; Paul-Ebhohimhen \& Avenell, 2007).

Over the past 30 years, numerous studies have demonstrated the efficacy of using financial incentives for initiating change in diet and physical activity. Unfortunately, among the small subset of studies that have continued to measure targeted health behavior(s) after an incentivization period ends, the general pattern observed is that maintenance of healthy changes is commonly very poor. Paul-Ebhohimhen \& Avenell's (2007) systematic review of financial incentives in treatments for obesity/overweight included just nine studies with follow-up of 1 year or more. Results showed that incentives produced no improvement in weight-loss maintenance at 12 or 18 months, after the incentives were removed; in fact, after 30 months of follow-up, there was a trend toward weight regain above baseline. A more recent systematic review of material incentives for weight loss conducted by Burns et al. (2012) similarly concluded that incentives are most effective in the short-run period of delivery (e.g., 6 months or less), but are less effective over longer periods, particularly if the incentives are discontinued. Adopting operant conditioning as their theoretical framework, Burns et al. highlight the fact that poor maintenance in this context is consistent with the classic principle of extinction (Skinner, 1974); however, a related set of principles derived from self-determination theory may offer additional insight. 


\section{Self-determination theory, incentives, and the undermining effect}

Self-determination theory (SDT; Deci \& Ryan, 1985; Deci \& Ryan, 2000) is one theory of human motivation that may provide insight into why some health behavior interventions emphasizing financial incentives struggle to achieve successful maintenance. At the core of SDT is the concept of self-determined or autonomous motivation, characterized by feeling a sense of freedom from extrinsic pressure. Autonomous motivation is often contrasted with controlled motivation, a category of motivation characterized by feeling coerced, either overtly by tangible rewards or punishments, or more subtly, as by emotional pressure from others or oneself. Following from the definitions of these two forms of motivation (autonomous vs. controlled), introducing performance-contingent extrinsic rewards (e.g., financial incentives) is known to increase controlled motivation, while reducing an individual's autonomous motivation for a targeted behavior.

Furthermore, when performance-contingent extrinsic rewards are introduced, they seem to reduce autonomous motivation not only while contingences are in place, but also well after the period when the rewards can be earned has ended. This pattern, often referred to as the "undermining effect," has been especially well studied in relation to tasks that have high baseline levels of a subset of autonomous motivation characterized by positive emotions like interest and enjoyment, also known as intrinsic motivation. Deci et al. (1999) conducted a meta-analysis of 128 studies testing this undermining effect, and found that groups who received performance-contingent rewards consistently reported lower levels of intrinsic motivation during a no-reward follow-up period relative to groups who received no reward. Furthermore, levels of intrinsic motivation during follow-up were often lower than at baseline. SDT posits that the negative relation between extrinsic rewards and intrinsic motivation can be explained by the fact that contingent rewards have a tendency to feel subtly controlling, thwarting people's psychological need for autonomy, and distracting them from potentially enjoyable aspects of the targeted activity. In these studies, intrinsic motivation was typically operationalized in two different ways, either using self-report measures or free-choice behavior. Free-choice behavior is defined as response rate in the absence of extrinsic contingences, and typically involves providing participants with a variety of activities to choose from in an unstructured environment (e.g., while left alone in a waiting room).

Athletic scholarships-One naturalistic context for exploring the relation between financial incentives and health behavior involves the longstanding tradition of offering athletic scholarships to college athletes. This represents an interesting case, as athletic scholarships are typically offered to only a fraction of the athletes on any given team, and only to those athletes who are achieving the highest level of performance. To the extent that people tend to enjoy activities more when they excel at them, this sets up a confound that might lead students with athletic scholarships to enjoy their chosen sport more than nonscholarship athletes. However, despite feeling more competent, a number of studies have found that student athletes with athletic scholarships enjoy playing sports less than their nonscholarships teammates (Ryan, 1977, 1980; Wagner et al., 1989; Medic et al., 2007). This effect has been attributed to athletes experiencing their performance-contingent scholarships as controlling. 


\section{Boring at baseline}

Although the vast majority of studies exploring the undermining effect have involved activities that people found highly interesting and enjoyable at baseline (e.g., a Soma puzzle or sport), a handful of small experiments included in the Deci et al. (1999) meta-analysis on this topic targeted activities that they described as "dull or boring." The average effect among the small experiments targeting dull-boring tasks was null. This led Deci et al. to conclude that there was not (yet) evidence for undermining in the context of dull-boring behaviors.

\section{Exploring the undermining effect in the context of healthy diet and activity interventions}

Healthy diet and activity interventions represent an interesting and underexplored context for testing the potential for extrinsic rewards to undermine intrinsic motivation. On the one hand, some healthy behaviors (e.g., preparing healthy meals and being physical active) have the potential to be highly interesting and enjoyable. On the other hand, other healthy behavior changes (e.g., avoiding saturated fat and television on the couch) have low potential for ever becoming interesting or enjoyable in and of themselves. Furthermore, eligibility criteria for such diet and activity interventions typically dictates that those receiving the intervention have only modest intrinsic motivation for the targeted healthy behaviors at baseline. Thus, it is unclear whether financial incentives (or any form of extrinsic reward) will undermine intrinsic motivation in this context.

A recent study by Moller et al. (2012) demonstrated that focusing on financial incentives in a healthy behavior change intervention (i.e., financial motivation) was unrelated to behavior or weight changes during a 3-week prescription phase while performance-contingent incentives were in place, but was negatively related to weight loss (men and women) and overall healthy change in diet and activity (men only) during a 17-week maintenance phase. However, this investigation did not directly analyze the relation between financial motivation and intrinsic motivation, or enjoyment of the targeted health behaviors. Burns and colleagues' (2012) subsequent systematic review of material incentives for weight loss concluded with an assertion that the role of motivation has received little direct attention in research on incentives and a call for more research that assesses motivation and subjective experience. A similar call for greater consideration of motivation in the context of research on financial incentives in health behavior change interventions, and specifically, the potential for undermining of intrinsic motivation, was echoed by Lynagh et al. (2013), and in a subsequent commentary by Hagger et al. (2013). After reviewing the literature on financial incentives and intrinsic motivation across behavioral health interventions, in general, Promberger and Marteau (2013) recently concluded that there was "no evidence" (yet) for undermining in this context, a finding they attributed to low levels of intrinsic motivation at baseline for targeted health behaviors.

The present investigation advances this line of research by testing whether financial motivation predicts a direct indicator of intrinsic motivation, changes in self-reported liking or enjoyment, related to health behaviors for which there were low levels of intrinsic motivation at baseline. This research has important implications for public health given the prevalent use of material incentives in healthy lifestyle interventions, and a growing 
evidence base linking affective attitudes and autonomous motivation to the successful maintenance of healthy behavior change (Mata et al., 2009; Silva et al., 2010, 2011; Teixeira et al., 2010; Williams et al., 1996).

\section{Method}

The study design and methods are described in detail in an open source Study Protocol paper published in BMC Public Health (Spring, et al., 2010), and will be described briefly below. Primary findings from the Make Better Choices trial were previously published in the Archives of Internal Medicine (Spring et al., 2012).

\section{Participants}

Chicago area adults between ages 21 and 60 years were recruited through community advertisements. To be eligible, individuals were required to report all of the following: (a) $<5$ servings of fruits and vegetables per day; (b) $>8 \%$ caloric intake from saturated fat; (c) $<60 \mathrm{~min} /$ day moderate/vigorous physical activity; and (d) $>90 \mathrm{~min} /$ day targeted sedentary screen time (television, movies, recreational internet use, and videogames). All procedures were approved by the Institutional Review Boards of the University of Illinois at Chicago and Northwestern University.

\section{Procedure}

Two-week baseline phase (and final eligibility screening)—Candidates who selfreported all four risk behaviors were screened by a Bachelor level research assistant (coach). The coach trained participants to accurately estimate and use a handheld device to record and upload dietary intake, moderate-vigorous intensity physical activity, and targeted recreational sedentary screen time. During the 2 -week baseline (run-in) phase, participants wore an accelerometer, recorded diet and activity on the handheld device, and submitted data daily to the coach.

Randomization-Candidates who displayed all four risk behaviors throughout baseline, as evidenced by handheld and accelerometer data, were randomized (stratified by gender) using a computer-generated sequence of randomly permuted blocks. The four behavioral intervention groups differed based on the behaviors that were targeted/incentivized. Each group was assigned to target a different combination of two behavior goals, one related to diet (fruit/vegetables or fat) and one related to activity (physical or sedentary activity): (1) increase fruit/vegetables and physical activity, (2) decrease fat and increase physical activity, (3) increase fruit/vegetables and decrease sedentary activity, or (4) decrease fat and sedentary activity.

Intervention phase-Coaches tailored behavioral strategies based on participants' baseline data. For example, those asked to decrease Fat were shown the ten foods that supplied their greatest saturated fat grams and coached to reduce portion size or number for those foods. For the first week of treatment, daily diet and activity goals were set mid-way between baseline behavior and the ultimate daily goal. From the second treatment week onward, full goals were set for the two targeted behaviors to which the participant was 
randomized: five fruit and vegetable servings, saturated fat intake $<8 \%$ of calories, physical activity $\checkmark 60 \mathrm{~min}$, or sedentary recreational activity $\$ 0 \mathrm{~min}$ per day. Participants were expected to reach their behavioral targets during treatment week 2 and to maintain them during week 3. During the three treatment weeks, they uploaded data daily and communicated as needed with their coaches via telephone or e-mail, per preference, to problem-solve around adherence barriers. When possible, coaches considered participants' individual preferences and tailored feedback in order to encourage greater enjoyment of healthy behavior change.

Performance-contingent financial incentives-During the 3-week intervention phase, participants could earn a $\$ 175$ incentive for fully meeting goals for both targeted behaviors. Thus, participants could earn just over \$50/week (\$175/3) for meeting their health behavior goals.

Handheld tool-Participants used a personal digital assistant to record and self-regulate their targeted behaviors. They were instructed to carry the device and record immediately after executing a behavior. During treatment and follow-up, the handheld device displayed two decision support feedback "thermometers" - one for diet and one for activity. Once activated, goal thermometers were continually updated in response to data entry. The goal thermometers also enabled participants to observe the potential impact of a food or activity choice.

\section{Measures}

Demographic information, anthropometric data, and motivation for health behavior change were assessed during screening. Demographic data gathered include: gender, age, ethnicity, marital status, education, income, and household size.

Financial motivation-Context-specific financial motivation for participating in the study was measured using modified items from the Motives for Physical Activities Measure (MPAM; Ryan et al., 1997). Items were modified to relate specifically to the healthy lifestyle intervention (targeting diet and activity, as opposed to physical activity, per se), and to reflect financial motivation. Before answering these questions, the nature of the study was explained to participants, and specifically, the potential for earning performance-contingent financial incentives in exchange for making healthy behavior changes. Seven items were altered to ask about eating as well as activity changes, and the degree to which financial incentives were a motive for participating in this diet-activity intervention study (e.g., "Because I want to earn extra money"; Mean $=3.90, \mathrm{SD}=.31, \alpha=.97)$. Participants responded on a 7 -point Likert scale $(1=$ not at all true for me; $7=$ very true for me).

General motivation-Modified items from the MPAM (Ryan et al., 1997) were also included to assess four additional motives, which have been included in previous research: fitness ( 5 items; Mean $=6.10, \mathrm{SD}=.16, \mathrm{a}=.79)$, appearance $(6$ items; Mean $=4.55, \mathrm{SD}=$. $92, \mathrm{a}=.88$ ), competence/challenge ( 7 items; Mean $=4.88, \mathrm{SD}=.89, \mathrm{a}=.79$ ), and enjoyment ( 7 items; Mean $=5.37, \mathrm{SD}=.58, \mathrm{a}=.80$ ). Items were modified to relate specifically to the healthy lifestyle intervention (targeting diet and activity, as opposed to 
physical activity, per se). Because the focus on the current investigation is Financial Motivation, we standardized each of the other four subscales, then combined them to create a composite measure of General Motivation (4 items; $\alpha=.78$ ). General Motivation was significantly correlated with Financial Motivation [r $(198)=.49, p<.001]$, and was included as a covariate in our analysis.

Enjoyment-Enjoyment (or liking) of each of the four health behaviors was assessed inperson at several time points: (1) at orientation, prior to the Baseline Phase, (2) immediately following the 2-week Baseline Phase, that is, immediately before the Intervention Phase began, and (3) again,immediately after the 3-week Intervention Phase ended.Before the 2week Baseline Phase began, participants filled out an extensive 40-item version of the Food Liking Questionnaire (10 sweet foods high in saturated fat, 10 savory foods high in saturated fat, 10 vegetables, and 10 fruits), and a 40-item version of the Activity Liking Questionnaire (10 moderate/vigorous intensity athletic activities, 10 moderate intensity work or household activities, 10 sedentary work or home-related activities, and 10 sedentary recreational activities including those targeted for change in the study, e.g., watching movies/television, or playing video games). For both the Food and Activity Liking Questionnaires, participants were asked to rate their preference for a food or activity using Rozin et al.'s (1991) 9-point hedonic scale (ranging from $1=$ dislike extremely, to $9=$ like extremely). Then at the beginning and end of the 3-week Intervention Phase, participants were asked to rate a subset of those foods and behaviors they previously rated as most enjoyable; the top rated four foods or activities were included for each behavior. Internal consistency of this scale was acceptably high for all four behaviors: Liking Fruits and Vegetables (Time 1 Mean $=5.89$, $\mathrm{SD}=1.84, \mathrm{a}=.76$; Time 2 Mean $=5.97, \mathrm{SD}=1.94, \mathrm{a}=.73$ ), Liking Fat (Time 1 Mean $=$ $6.75, \mathrm{SD}=1.85, \mathrm{a}=.56$; Time 2 Mean $=6.45, \mathrm{SD}=1.93, \mathrm{a}=.67$ ), Liking Physical Activity (Time 1 Mean = 5.45, $\mathrm{SD}=2.13, \mathrm{a}=.69$; Time 2 Mean $=5.77, \mathrm{SD}=2.05, \mathrm{a}=.68$ ), and Liking Sedentary Activity (Time 1 Mean $=7.15, \mathrm{SD}=1.70, \mathrm{a}=.48$; Time 2 Mean $=7.09$, $\mathrm{SD}=1.75, \mathrm{a}=.63$ ).

\section{Results}

\section{Study sample}

The final sample of 204 adults included 48 males; $46.6 \%$ minorities; $25 \%$ with no more than a high school education; and mean age 33.3 years (s.d. $=11.04)$. Except for one individual, all participants attained behavioral targets during the 3-week initiation period (thus earning the $\$ 175$ performance-contingent incentive); the majority did so promptly. The median time taken to achieve consumption of five fruit/vegetables was 9 days (i.e., 2 days after the full five servings goal was set). The median time taken to attain each of the other goals (sedentary activity, physical activity, or fat intake) was 8 days (i.e., 1 day after the targeted amount was set as a goal). Table 1 describes demographics of sample participants with high versus low Financial Motivation.

\section{Group effects}

Group effects have been reported previously (Spring et al., 2012). The primary finding was that the group assigned to increase fruits/vegetables and decrease sedentary time produced 
significantly greater change in Composite Diet-Activity Improvement Score after the 3week Intervention Phase, relative to the other three groups. Further, the increase fruits/ vegetables and decrease sedentary time group maintained this advantage through the end of the 17-week Follow-up Phase.

The effects reported herein related to Financial Motivation were independent of Group assignment. Group assignment did not predict changes in liking any of the four health behaviors $(p \geq .71)$, and none of the Financial Motivation $\times$ Group interactions were significant; thus, all secondary analysis reported in this paper were conducted collapsing across Groups.

\section{Financial motivation and intrinsic motivation}

Preliminary analysis-As a first step, we calculated raw change in liking each behavior from Time 1 to Time 2, then correlated these change scores with Financial Motivation (controlling for General Motivation). Financial Motivation was associated with maladaptive changes in enjoyment; a positive partial correlation with changes in liking fat $\left(\mathrm{r}_{\mathrm{p}}=.18, p<\right.$. $05)$, and a negative correlation with changes in liking physical activity $\left(\mathrm{r}_{\mathrm{p}}=-.18, p<.05\right)$ and fruits/vegetables $\left(\mathrm{r}_{\mathrm{p}}=-.16, p<.05\right)$. The correlation between Financial Motivation and change in liking sedentary activity was nonsignificant $\left(\mathrm{r}_{\mathrm{p}}=.12, p=.13\right)$.

MANCOVA-In order to plot the pattern of changes in liking each behavior as a function of Financial Motivation, a repeated measures Multivariate Analysis of Covariance (MANCOVA) was performed testing the interaction between Time (2: baseline; week 3) and Group (4: increase fruits/vegetables and decrease sedentary time; increase fruits/ vegetables and physical activity; decrease fat and sedentary time; decrease fat and increase physical activity), including Financial Motivation (1) and General Motivation (1) as covariates. The model specified all three mixed-level 2-way interactions, including Group $\times$ Time, Financial Motivation $\times$ Time, and General Motivation $\times$ Time. The critical multivariate interaction for this study was Financial Motivation $\times$ Time, which was significant, Wilks' Lambda $=.975, F(4,163)=3.83, p=.005$, partial $\eta^{2}=.024$. The Group $\times$ Time and General Motivation $\times$ Time interactions were both nonsignificant. We next explored the Financial Motivation $\times$ Time interactions predicting changes in liking for each of the four health behaviors.

Fruits/vegetables-The between-participants main effect for Financial Motivation was nonsignificant, $F(1,166)=.23, p=.63$; however, the Financial Motivation $\times$ Time interaction predicting changes in liking fruits/vegetables was significant, $F(1,166)=4.49, p$ $=.036$, partial $\eta^{2}=.027$ (see Fig. 1a).

Fat-The between-participants main effect for Financial Motivation was marginally significant, $F(1,166)=3.16, p=.077$; and the Financial Motivation $\times$ Time interaction predicting changes in liking saturated fat was significant, $F(1,166)=4.49, p=.035$, partial $\eta^{2}=.032$ (see Fig. 1b). 
Physical activity-The between-participants main effect for Financial Motivation was nonsignificant, $F(1,166)=2.14, p=.15$; and the Financial Motivation $\times$ Time interaction predicting changes in liking physical activity was significant, $F(1,166)=6.13, p=.014$, partial $\eta^{2}=.037$ (see Fig. 1c).

Sedentary activity-In this model, the between-participants main effect for Financial Motivation was significant, $F(1,166)=7.70, p=.006$, partial $\eta^{2}=.047$; and the Financial Motivation $\times$ Time interaction predicting changes in liking sedentary leisure activities was nonsignificant, $F(1,166)=2.26, p=.135$, partial $\eta^{2}=.014$ (see Fig. $1 \mathrm{~d}$ ).

Exploratory tests of whether gender or socio-economic status (SES) moderated the associations between Financial Motivation and changes in enjoyment for each of the four behaviors (Financial Motivation $\times$ Time) revealed no significant 3 -way interactions. ${ }^{1}$

\section{Discussion}

The current investigation tested the hypothesis that relatively high financial motivation for participating in an intensive diet and activity intervention (that is, motivation derived from financial incentives) would undermine potential increases in enjoyment of healthy behaviors and potential decreases in enjoyment for unhealthy behaviors. The Make Better Choices trial targeted four behaviors related to diet and activity, two healthy behaviors and two unhealthy behaviors: (1) increasing fruit and vegetable intake, (2) decreasing saturated fat intake, (3) increasing physical activity, and (4) decreasing sedentary leisure screen time. The primary hypothesis was supported. After controlling for general motivation to participate, high financial motivation negatively predicted changes in liking both healthy behaviors, physical activity and fruits and vegetables. Relatively high financial motivation was also positively related to changes in liking foods high in saturated fat, a maladaptive pattern. Financial motivation was not significantly related to changes in liking sedentary leisure screen time. Plotting these effects revealed that across all four behaviors high financial motivation during the MBC intervention was actually associated with little changes in liking; whereas low Financial Motivation was associated with a healthy pattern of change (greater liking for physical activity and fruits/vegetables; less liking for saturated fat). In other words, high financial motivation seems to have undermined or suppressed participants' potential for growing to enjoy healthy behaviors, and dislike unhealthy behaviors.

This research, in conjunction with findings from the $\mathrm{MBC} 1$ trial previously reported by Moller et al. (2012), represents, to the best of our knowledge, the first direct evidence for (a) the undermining of potential enjoyment for healthy behaviors, and (b) the suppression of

\footnotetext{
${ }_{1}^{1}$ Moderation: Gender To investigate whether gender moderated the relation between Financial Motivation and changes in liking FV, Fat, PA, and Sed, we next ran the above MANCOVA model adding Gender, and the 3-way interaction of Financial Motivation $\times$ Time $\times$ Gender. This 3-way interaction did not significantly predict changes in liking $\mathrm{FV}[F(1,167)=0.62, p=.43]$, liking Fat $[\mathrm{F}(1,167)=$ $0.04, p=.85]$, liking PA $[F(1,167)=1.28, p=.26]$, or liking $\operatorname{Sed}[F(1,167)=1.27, p=.26)]$.SES To investigate whether socioeconomic status moderated the relation between Financial Motivation and changes in liking FV, Fat, PA, and Sed, we next ran the above MANCOVA model adding estimates of household income, and the 3-way interaction of Financial Motivation $\times$ Time $\times$ Income. This 3-way interaction did not significantly predict changes in liking $\mathrm{FV}[F(1,167)=1.76, p=.19]$, liking Fat $[\mathrm{F}(1,167)=$ $0.23, p=.63]$, liking PA $[F(1,167)=0.64, p=.43]$, or liking Sed $[F(1,167)=0.98, p=.33)]$. We note, however, that our measure of annual household income was negatively skewed; the modal response $(28 \%)$ reported an annual household income greater than $\$ 75,000$, potentially suppressing our ability to detect Financial Motivation $\times$ Time $\times$ Income interactions.
} 
potentially reduced enjoyment for unhealthy behaviors within the context of an intensive diet and activity intervention. In a preliminary set of related findings reported by Moller et al. (2012), high financial motivation among MBC1 participants was shown to undermine maintenance of healthy behavior change; however, this pattern of undermined behavioral maintenance could have been attributed to numerous psychological mechanisms. The current investigation supports a new hypothesis that emphasizing financial incentives in health behavior change interventions may have negative affective consequences, undermining potential increases in enjoyment for healthy behaviors and potential decreases in the enjoyment of unhealthy behaviors. Testing this causal hypothesis, regarding the relative emphasis or prominence of financial incentives, represents an important direction for future research.

\section{Limitations}

The strongest limitation associated with this study concerns the correlational, as opposed to experimental, nature of these data. In the MBC trial, although financial incentives were contingent on changing different behaviors based on group assignment, all participants received the same financial incentives in terms of schedule and potential value. As a result, the focal predictor was self-reported financial motivation, the degree to which participants acknowledged that the financial incentives were a relatively important reason for their decision to participate. Correlational associations of this kind raise concerns about the potential for illusory correlations, whereby a third variable (correlated with both financial motivation and changes in liking healthy and unhealthy behaviors during the incentivized phase of the study) may explain the observed relation. We have done our best to rule out this concern by controlling for several potential third variables, including general motivation, gender, and social-economic status. Future studies may also control for individual differences in general causality orientations, which have been shown to moderate the undermining effect of rewards on intrinsic motivation in a lab setting (Hagger \& Chatzisarantis, 2011). Furthermore, a very natural direction for this line of research will involve experimentally testing the hypothesis that emphasizing financial incentives (particularly in a manner likely to be perceived as controlled) will undermine adaptive changes in enjoyment and maintenance in a diet and activity intervention.

On this note, we also seek to have recognized the significant challenges associated with testing this hypothesis experimentally, which we believe also speaks to the value of the correlational approach adopted for this study. According to self-determination theory, the provision of financial incentives will undermine intrinsic motivation only to extent that those incentives are perceived as controlling or manipulative. Institutional Review Boards are sensitive to this issue, and will not permit research that uses financial incentives in overtly controlling ways. On the other hand, private companies, many of which are already using financial incentives as a component of employee wellness programming, are rarely limited by Institutional Review Boards. Furthermore, a key aspect of what makes financial incentives feel controlling (or not) is the interpersonal context under which they are offered (Hagger et al., 2013; Moller \& Deci, in press; Ryan et al., 1983). Participants in studies conducted at research institutions typically have little to no prior relationship with the individual offering the financial incentive, thereby limiting the degree to which financial 
incentives will be interpreted as controlling. Employers, by contrast, typically have a rich interpersonal history with employees prior to introducing a wellness program featuring financial incentives. As a result, we believe more subjectively controlling forms of incentivization for health behavior change are common in applied settings, but difficult to study, as access is typically limited, and industry sponsored research often goes unpublished.

The present investigation offers an important contribution to this literature in terms of informing both basic science and clinical practice. Nearly all of the hundred plus studies on the undermining effect have involved lab experiments with relatively small samples, rewards administered at a single time point, and behaviors with high levels of baseline intrinsic motivation (see Deci et al.'s 1999 meta-analytic review). By contrast, this research provides evidence for the undermining effect in a study with a relatively large sample ( $\mathrm{n}=$ 204), an extended incentivization period (3-week), and that targeted behaviors for which there was only modest levels of intrinsic or autonomous motivation at baseline (i.e., fruit/ vegetable intake and physical activity). Further, the study established that financial incentives may also suppress the potential for growing to enjoy unhealthy behaviors less (i.e., saturated fat intake); a phenomenon that, to the best of our knowledge, is entirely new to this literature. In sum, these findings suggest that emphasizing financial incentives in the context of an intensive diet and activity intervention can have inimical consequences, and that researchers and practitioners should exercise caution when using financial incentives in this context. The findings have especially high public health significance in light of the already rampant and by some indications growing use of this tool in behavioral health interventions.

\section{Acknowledgments}

The Make Better Choices trial was supported by National Institutes of Health (NIH) grant HL075451 to Dr. Spring, by the Robert H. Lurie Comprehensive Cancer Center Grant (NIH P30 CA060553), and by NIH F31 MH070107 to Dr. Schneider. We thank Sarah Altman, Katherine Bailey, Katty Cavero, Michael J. Coons, Neil Doran, Anne Maloney, Dennis McChargue, Sherry Pagoto, Anjali Pandit, Jim Painter, Michael Painter, Christine Dutton Pellegrini, Alex Pictor, Natalie Ritchie, Megan Roehrig, and Stephanie Russell for their contributions and technical assistance.

\section{References}

Burns RJ, Donovan AS, Ackermann RT, Finch EA, Rothman AJ, Jeffery RW. A theoretically grounded systematic review of material incentives for weight loss: Implications for interventions. Annals of Behavioral Medicine. 2012; 44:375-388. [PubMed: 22907712]

Deci EL, Koestner R, Ryan RM. A meta-analytic review of experiments examining the effects of extrinsic rewards on intrinsic motivation. Psychological Bulletin. 1999; 125:627-668. [PubMed: 10589297]

Deci, EL.; Ryan, RM. Intrinsic motivation and self-determination in human behavior. Plenum; New York: 1985.

Deci EL, Ryan RM. The "what" and "why" of goal pursuits: Human needs and the self-determination of behavior. Psychological Inquiry. 2000; 11:227-268.

Hagger MS, Chatzisarantis NLD. Causality orientations moderate the undermining effect of rewards on intrinsic motivation. Journal of Experimental Social Psychology. 2011; 47:485-489.

Hagger MS, Keatley DA, Chan DCK, Chatzisarantis NLD, Dimmock JA, Jackson B, et al. The goose is (half) cooked: A consideration of the mechanisms and interpersonal context is needed to elucidate the effects of personal financial incentives on health behavior. International Journal of Behavioral Medicine. 2013 doi:10.1007/s12529-013-9317-y. 
Lussier JP, Heil SH, Mongeon JA, Badger GJ, Higgins ST. A meta-analysis of voucher-based reinforcement therapy for substance use disorders. Addiction. 2006; 101:192-203. [PubMed: 16445548]

Lynagh MC, Sanson-Fisher RW, Bonevski B. What's good for the goose is good for the gander. Guiding principles for the use of financial incentives in health behaviour change. International Journal of Behavioral Medicine. 2013; 20:114-120. [PubMed: 22094998]

Mata J, Silva MN, Vieira PN, Carra EV, Andrade AM, Coutinho SR, et al. Motivational "spill-over" during weight control: Increased self-determination and exercise intrinsic motivation predict eating self-regulation. Health Psychology. 2009; 28:709-716. [PubMed: 19916639]

Medic N, Mack DE, Wilson PM, Starkes JL. The effects of athletic scholarships on motivation in sport. Journal of Sport Behavior. 2007; 30:292-306.

Moller, AC.; Deci, EL. Psychology of getting paid: An integrated perspective.. In: Bijleveld, E.; Aarts, H., editors. The psychological science of money. Springer; (in press)

Moller AC, McFadden HG, Hedeker D, Spring B. Financial motivation undermines maintenance in an intensive diet and activity intervention. Journal of Obesity. 2012 doi:10.1155/2012/740519.

National Business Group on Health and Fidelity Investments Benefits Consulting. Employer investments in improving employee health. 2013. Retrieved from http:// www.businessgrouphealth.org/pressroom/pressRelease.cfm?ID=207

Paul-Ebhohimhen V, Avenell A. Systematic review of the use of financial incentives in treatments of obesity and overweight. Obesity Reviews. 2007; 9:355-367. [PubMed: 17956546]

Promberger M, Marteau TM. When do financial incentives reduce intrinsic motivation? Comparing behaviors studied in psychological and economic literatures. Health Psychology. 2013; 32:950957. [PubMed: 24001245]

Rozin P, Levine E, Stoess C. Chocolate craving and liking. Appetite. 1991; 17:199-212. [PubMed: 1799282]

Ryan, ED. Attribution, intrinsic motivation, and athletics.. In: Gedvilas, LI.; Kneer, ME., editors. National College Physical Education Association for Men/National Association for Physical Education of College Women. National Conference. Office of Publications Services; Chicago, IL: 1977. p. 346-353.

Ryan, ED. Attribution, intrinsic motivation, and athletics: A replication and extension.. In: Nadeau, CH.; Halliwell, WR.; Newell, KM.; Roberts, GC., editors. Psychology of motor behavior and sport. Human Kinetics; Champaign, IL: 1980. p. 19-26.

Ryan RM, Frederick CM, Lepes D, Rubio N, Sheldon KM. Intrinsic motivation and exercise adherence. International Journal of Sport Psychology. 1997; 28:335-354.

Ryan RM, Mims V, Koestner R. Relation of reward contingency and interpersonal context to intrinsic motivation: A review and test using cognitive evaluation theory. Journal of Personality and Social Psychology. 1983; 45:736-750.

Silva MN, Markland D, Vieira PN, Carraca EV, Vieira PN, Coutinho SR, et al. Exercise autonomous motivation predicts 3-yr weight loss in women. Medicine and Science in Sports and Exercise. 2011; 43:728-737. [PubMed: 20689448]

Silva MN, Vieira PN, Coutinho SR, Minderico CS, Matos MG, Sardinha LB, et al. Using selfdetermination theory to promote physical activity and weight control: A randomized controlled trial in women. Journal of Behavioral Medicine. 2010; 33:110-122. [PubMed: 20012179]

Skinner, BF. About Behaviorism. Knopf; New York: 1974.

Spring B, Schneider K, McFadden HG, Vaughn J, Kozak AT, Smith M, et al. Multiple behavior change in diet and activity: A randomized controlled trial using mobile technology. Archives of Internal Medicine. 2012; 72:789-796. [PubMed: 22636824]

Spring B, Schneider K, McFadden HG, Vaughn J, Kozak AT, Smith M, et al. Make Better Choices (MBC): Study design of a randomized controlled trial testing optimal technology-supported change in multiple diet and physical activity risk behaviors. BMC Public Health. 2010; 10:586. [PubMed: 20920275]

Teixeira PJ, Silva MN, Coutinho SR, Palmeira AL, Mata J, Vieira PN, et al. Mediators of weight loss and weight loss maintenance in middle-aged women. Obesity. 2010; 18:725-735. [PubMed: 19696752] 
Wagner SL, Lounsbury JW, Fitzgerald LG. Attribute factors associated with work/leisure perceptions. Journal of Leisure Perceptions. 1989; 21:155-166.

Williams GC, Grow VM, Freedman Z, Ryan RM, Deci EL. Motivational predictors of weight-loss and weight-loss maintenance. Journal of Personality and Social Psychology. 1996; 70:115-126.

[PubMed: 8558405] 
(a) Fruits \& Vegetables*

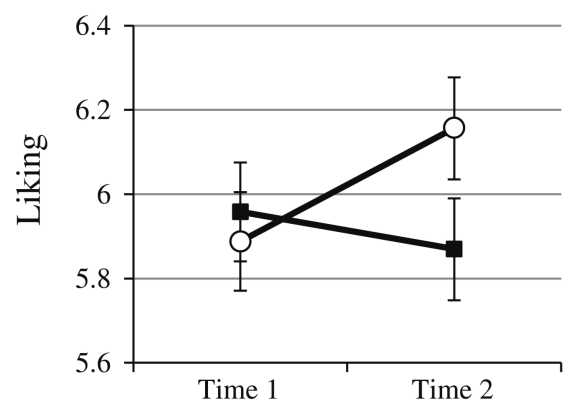

(c) Physical Activity*

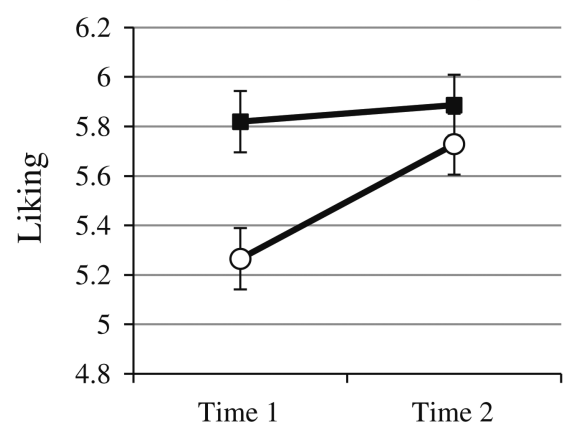

(b) Saturated Fat*

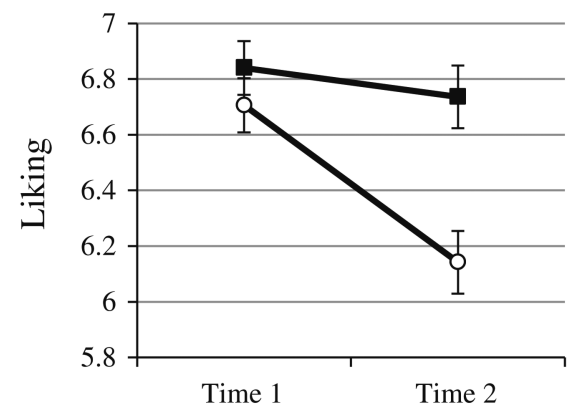

(d) Sedentary Leisure

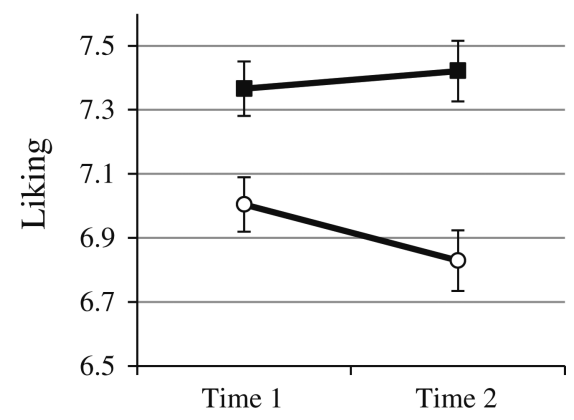

Fig. 1.

Financial motivation predicting changes in liking (FV, Fat, PA, and Sed). a Fruits and vegetables*. b Saturated fat*. c Physical activity* d Sedentary leisure. Note: Asterisk indicates a significant financial motivation $\times$ time interaction. The "High" and "Low" financial motivation slopes represent predicted slopes associated with plus and minus one standard deviation from the sample mean, respectively, on the continuous financial motivation scale. Key: $-\mathbf{m}-$ High Financial Motivation (+1 SD), $\longrightarrow-$ - Low Financial Motivation (-1 SD) 


\section{Table 1}

Demographics of participants with high versus low financial motivation

\begin{tabular}{llll}
\hline & $\begin{array}{l}\text { High financial motivation }(\mathbf{n}= \\
\mathbf{1 0 7})\end{array}$ & $\begin{array}{l}\text { Low financial motivation }(\mathbf{n}= \\
\mathbf{9 7})\end{array}$ & Full sample $(\mathbf{n}=\mathbf{2 0 4})$ \\
\hline Mean age years (SD) & $29.80(11.70)$ & $36.14(9.38)$ & $33.3(11.04)$ \\
$\%$ female $(\%)$ & 76 & 77 & 76 \\
$\%$ minorities $(\%)$ & 47.7 & 45.4 & 46.6 \\
$\%$ with household income $\$$ \$ $\$$ k $/$ year $(\%)$ & 22 & 35 & 28 \\
\hline
\end{tabular}

For the purpose of reporting the above descriptive data, financial motivation was dichotomized using a median split to categorize scores as "High" versus "Low." In all subsequent analyses, financial motivation was treated as a continuous variable 